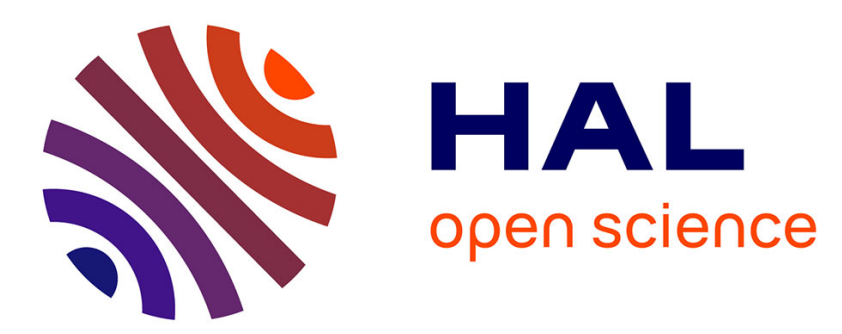

\title{
Modeling of Connections Taking Into Account Return Plane: Application to EMI Modeling for Railway
}

\author{
Edith Clavel, James Roudet, Thierry Chevalier, Dragos Postariu
}

\section{To cite this version:}

Edith Clavel, James Roudet, Thierry Chevalier, Dragos Postariu. Modeling of Connections Taking Into Account Return Plane: Application to EMI Modeling for Railway. IEEE Transactions on Industrial Electronics, 2009, 56 (3), pp 678-684. hal-00373558

\section{HAL Id: hal-00373558 https://hal.science/hal-00373558}

Submitted on 6 Apr 2009

HAL is a multi-disciplinary open access archive for the deposit and dissemination of scientific research documents, whether they are published or not. The documents may come from teaching and research institutions in France or abroad, or from public or private research centers.
L'archive ouverte pluridisciplinaire HAL, est destinée au dépôt et à la diffusion de documents scientifiques de niveau recherche, publiés ou non, émanant des établissements d'enseignement et de recherche français ou étrangers, des laboratoires publics ou privés. 


\title{
Modeling of Connections Taking Into Account Return Plane: Application to EMI Modeling for Railway
}

\author{
Edith Clavel, James Roudet, Thierry Chevalier, and Dragos Mihai Postariu
}

\begin{abstract}
The modeling of electrical characteristics of connections is an important stage of the design phase of a structure. Indeed, they have an impact on the current density distributions inside conductors as well as on the current distributions when several components are connected in parallel. In the case of a return plane in the studied structure as for power electronics converters or railway applications, the model of connections has to be improved in order to represent the physics better. For the first application field, the cooling system itself can be a ground plane, and for the second one, the earth has to be modeled. This paper presents different ways to take into account a return plane while modeling the electrical equivalent circuit of connections above it. It starts with the simplest one, the image method, and continues with the use of a complex skin depth result of solving the Carson integral.
\end{abstract}

Index Terms-Electromagnetic interference (EMI) modeling, equivalent impedance, finite-element method (FEM), partialelement equivalent circuit (PEEC) method, railway system, transmission line modeling.

\section{INTRODUCTION}

$\mathbf{T}$ HE electrical modeling of connections is unavoidable today, whether the applications concern a power electronics structure, a power distribution bus bar, or a railway system.

Indeed, for power distribution purposes, the internal electrical characteristics of conductors lead to supplementary losses which imply over costs for the life cycle analysis of the product. Moreover, current levels inside these conductors can be high which can lead to an over heating of the structure. Dissipating these losses can be difficult.

In the power electronics field, it consists of controlling the value of the impedance of the commutation loop in order to have a good working of the static converter. Moreover, when several semiconductors are connected in parallel, it is necessary to have an equal distribution of current inside them. Now,

Manuscript received February 15, 2008; revised September 29, 2008. First published November 18, 2008; current version published February 27, 2009.

E. Clavel is with the Grenoble Génie Electrique Laboratory, 38402 Grenoble, France, and also with the University Joseph Fourier, 38041 Grenoble, France (e-mail: edith.clavel@g2elab.inpg.fr).

J. Roudet is with the Power Electronics Team, Grenoble Génie Electrique Laboratory, University Joseph Fourier, 38041 Grenoble, France.

T. Chevalier is with the Grenoble Génie Electrique Laboratory, 38402 Grenoble, France, and also with the National Polytechnic Institute of Grenoble, 38031 Grenoble, France.

D. M. Postariu is with the Grenoble Génie Electrique Laboratory, 38402 Grenoble, France.

Color versions of one or more of the figures in this paper are available online at http://ieeexplore.ieee.org.

Digital Object Identifier 10.1109/TIE.2008.2008344 everyone knows that the electrical characteristics of the layout have an effect on the balance of currents.

For these two kinds of applications, conductors are very often near a return plane which can be the earth for railway applications or the cooling system for power electronics structures.

While modeling the connections of every kind of electrical devices, it is then necessary to take into account the characteristics of this ground plane. Accordingly, the application assumptions will be different, and then, the modeling method must be adapted.

In this paper, different modeling approaches are presented according to the studied application. Section II is dedicated to the modeling method which is commonly used to evaluate the electrical characteristics of conductors. In Section III, the influence of a perfect ground plane is recalled. The characteristics of a nonperfect ground plane are progressively inserted in Section IV, and the appropriate methods are presented. Finally, the application of the modeling of a railway system is detailed in Section V.

\section{Modeling of Connections}

The intrinsic electrical characteristics of conductors can be taken into account by using different methods. However, the most convenient model is an electrical equivalent circuit. This model is based on the partial element equivalent circuit (PEEC) method. In [1] and [2], Ruehli details the modeling approach.

Assuming uniform current density inside the cross sections of conductors and nonmagnetic materials (i.e., relative permeability equal to 1 ), the value of electrical characteristics is obtained using analytical formulas. A nonuniform current density is modeled using a meshing of a conductor. It is not necessary to mesh the air around the studied device, which is a great advantage compared with the finite-element method (FEM).

According to the application field, the analytical formulations will be different.

Indeed, for a low-frequency model (until some megahertz), it is not necessary to take into account the propagation along the conductors, and the modeling process is shown in Fig. 1. According to the assumption upon the current direction inside conductors, the description will be pipe oriented or 2-D. The meshing is adapted to this description. Then, the following stages of the modeling consist of evaluating the values of electrical components using analytical formulations and solving the Kirchoff equations to obtain the currents, the losses for instance. 


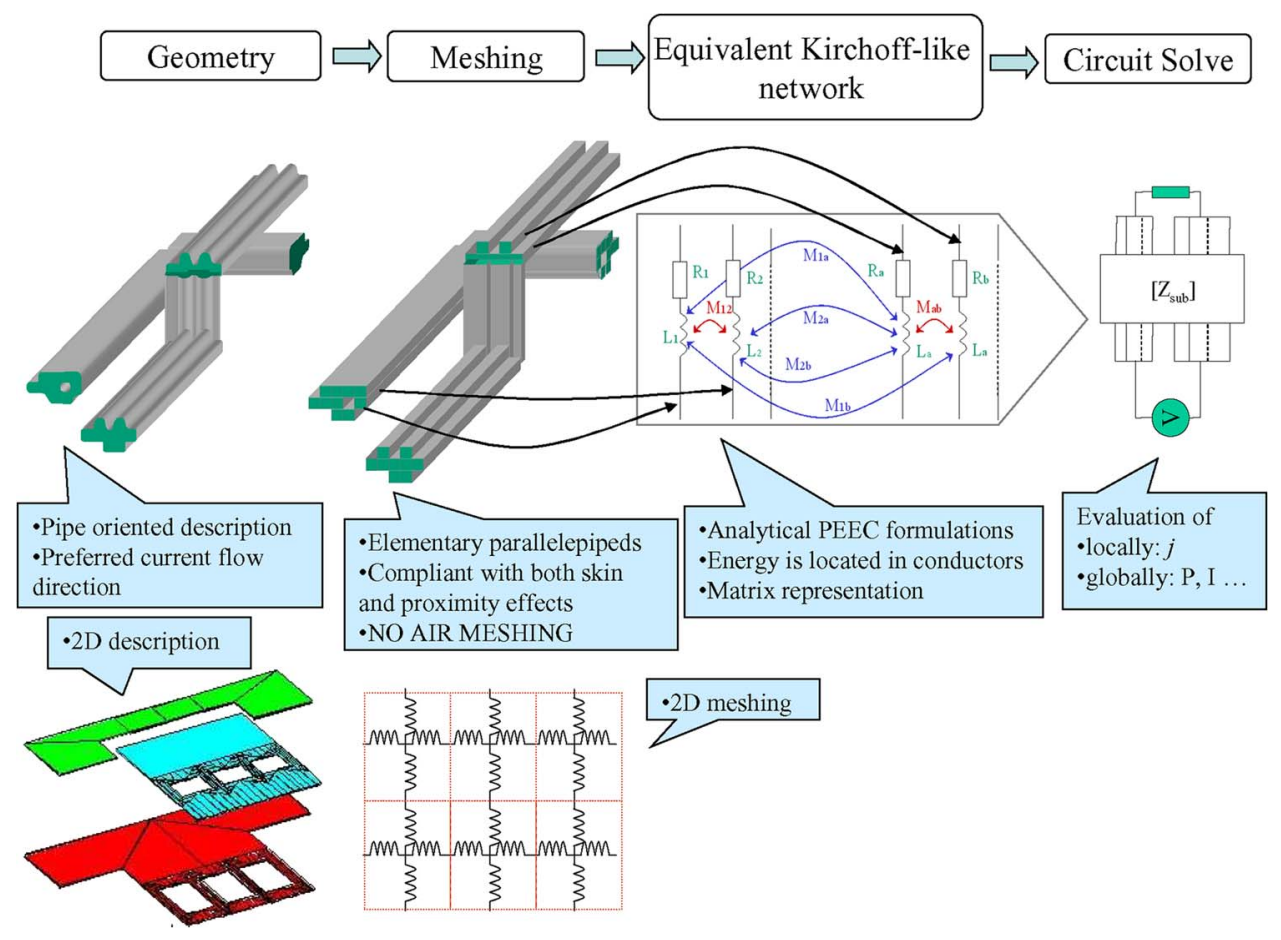

Fig. 1. Principle of the PEEC method.
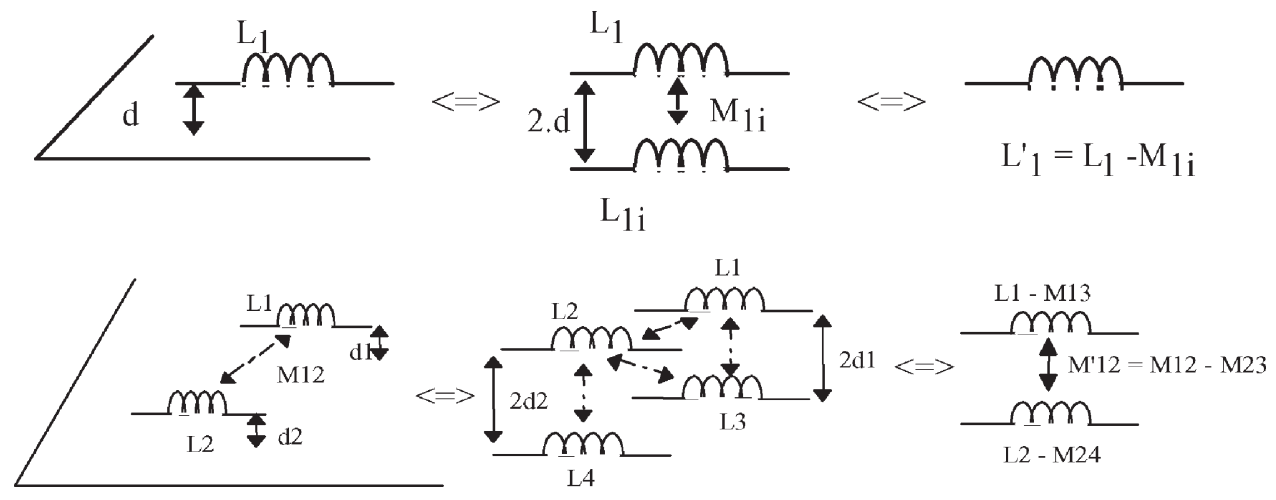

Fig. 2. Image method principle.

This method has been widely used in order to evaluate the electromagnetic interference (EMI) performance of power converters [3], [4], thanks to the development of the software InCa3D. ${ }^{1}$

For high frequencies, the PEEC approach is adapted for transmission line purposes, which is called multiconductor transmission lines (MTL) [5]. The principle of modeling is the same; only the formulations change.

\section{IMAge Method}

In the case of a perfect ground plane, e.g., infinite sizes and conductivity, it is possible to use the well-known image method to introduce the influence of the ground plane upon the electrical characteristics of conductors.

In one word, the values of the intrinsic inductances of conductors as well as the values of mutual inductances between conductors are modified.

\footnotetext{
${ }^{1}$ [Online]. Available: http://www.cedrat-groupe.com/.
}

Fig. 2 shows the principle and the results.

For a large number of applications, this modeling is a good approximation. It remains easy to apply and understand.

\section{Modified Image Method}

\section{A. Case of High Conductivity}

For a return plane of high conductivity, e.g., for copper or aluminum, the image method remains quite well adapted.

However, for some power electronics applications, it is not possible to assume infinite sizes of the return plane. For instance, the thickness of ground plane of the insulated metallic substrate (IMS) applications is very low, and the assumption of infinite sizes for the image method is not verified specially for low frequencies.

In this case, it is possible to adapt the image method. Indeed, the distance between the conductor and its image is modified. For the image method, this distance is equal to $2 d$ where $d$ is the distance between the return plane and the conductor. Here, we 


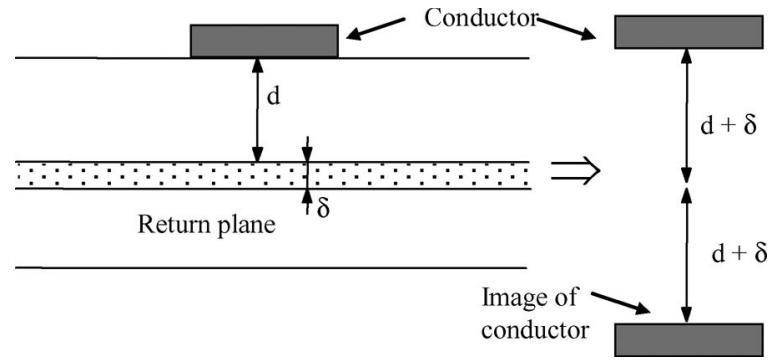

Fig. 3. Modified image method.

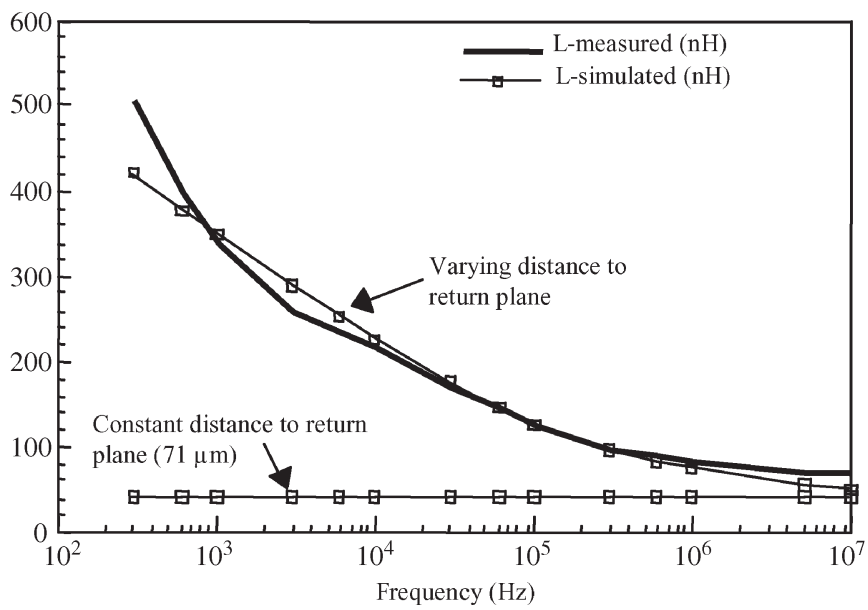

Fig. 4. Inductance of an IMS loop with return plane: comparison between modeling and measurements.

propose to equal this distance to $2(d+\delta)$ where $\delta$ is the skin depth as Deri et al. also proposed [6] (Fig. 3).

For this case, it is not the complex skin depth.

It is defined in the following where $\mu$ is the permeability, $\sigma$ is the conductivity, and $f$ is the frequency:

$$
\delta=\sqrt{\frac{2}{\omega \mu \sigma}}=\frac{1}{\sqrt{\pi f \mu \sigma}} .
$$

This has been applied to an IMS structure, and the value of the equivalent inductance of the modeling has been compared to measurements. Indeed, when frequency increases, the distance between the conductor and its image decreases compared to a constant value for the image method.

In Fig. 4, the two models are compared with measurements.

With this model, the influence of the return plane is only on the value of the inductances and mutual inductances of conductors. Indeed, since geometry has been meshed to take into account nonuniform current density, when circuit equations are solved, this influence appears on the real part of the equivalent impedance and, therefore, on the global losses of the structure.

\section{B. Case of Earth Return Plane}

However, in some cases, the assumption of a high conductivity of the return plane is not verified, like for the earth in the railway system. Hence, the Carson's integral [7] has to be solved in order to take into account the return plane and to obtain an electrical equivalent circuit of this part of the structure.
Different solutions have been proposed to solve the Carson's integral. Some are based on a truncation of the Bessel function used; others propose a double logarithmic approximation [8]. However, since it is more convenient to work with an equivalent circuit, in this paper, we propose to continue the use of the image method and, then, to apply the Deri solution [6].

For this case, the distance between the conductor and its image is increased by the complex skin depth $\underline{\delta}$

$$
\underline{\delta}^{2}=\frac{1}{j \omega \mu \sigma} .
$$

In the example of one conductor above a return plane (Fig. 2), its self-inductance is given by

$$
\begin{aligned}
L & =\frac{\mu_{0}}{8 \pi}+\frac{\mu_{0}}{2 \pi} \ln \left(\frac{2 d}{r}\right)+\frac{\mu}{\pi} J_{\text {ground }} \\
\text { with } J_{\text {ground }} & =\int_{0}^{\infty} \frac{\exp (-2 d x)}{x+\sqrt{x^{2}+j \omega \mu \sigma}} d x
\end{aligned}
$$

where $d$ is the distance between the conductor and the return plane, $r$ is the radius of the conductor, and $x$ is the frequencydependent conductivity of the earth.

A simple variable change [(4)] and two successive approximations [(5) and (6)] lead to

$$
\begin{aligned}
x & =\frac{u}{2 \underline{\delta}} \\
\frac{u}{\frac{u}{2}+\sqrt{\left(\frac{u}{2}\right)^{2}+1}} & \approx 1-\exp (-u) \\
\int_{0}^{\infty} \frac{\exp (-a x)-\exp (-b x)}{x} d x & \approx \ln \left(\frac{b}{a}\right) \\
J_{\text {ground }} & =\frac{1}{2} \ln \left(\frac{d+\underline{\delta}}{d}\right) .
\end{aligned}
$$

Once again, the distance between conductor and its image is modified.

The value $d+\underline{\delta}$ is a complex number which is possible to write as a modulus and phase. Then, we can see that $J_{\text {ground }}$ is also a complex number. Therefore, not only the inductance of conductor $L_{\mathrm{c}}$ is modified with this approach but also the resistive part of the conductor. That way, the influence of finite conductivity of return plane is modeled through the following electrical characteristics:

$$
\begin{aligned}
d+\underline{\delta} & =h \exp (-j \theta) \\
L_{c} & =\frac{\mu_{0}}{8 \pi}+\frac{\mu_{0}}{2 \pi} \ln \left(\frac{2 d}{r}\right)+\frac{\mu}{2 \pi} \ln \left(\frac{h}{d}\right) \\
Z_{c} & =R_{c}+\frac{\mu \omega}{2 \pi} \theta+j L_{c} \omega
\end{aligned}
$$

with $R_{\mathrm{c}}$ as the resistance of the conductor.

The same approach can be undertaken for two conductors above a return plane in order to evaluate the influence of 


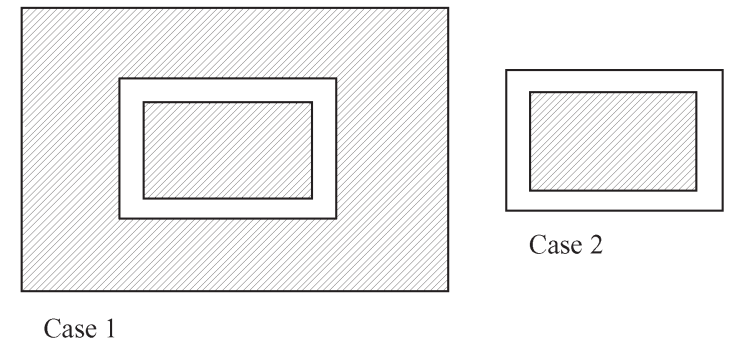

Loop inductance $(\mathrm{nH})$

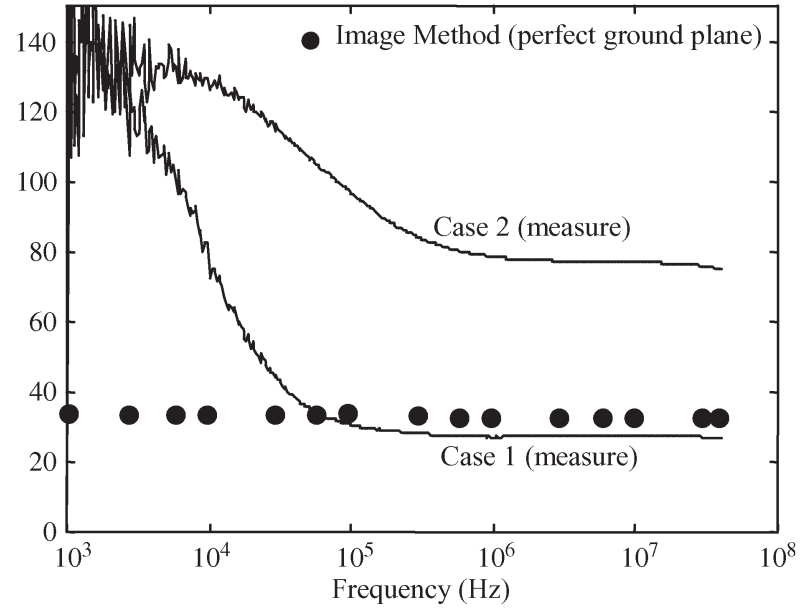

Fig. 5. Inductance of loop with two return planes: comparison between (dotted line) modeling and measurements.

this plane upon the mutual inductance between these two conductors.

The solving steps are the same, and once again, the conclusion is to modify the distance between conductors and images introducing the complex skin depth. Not only the imaginary part but also the real part of the intrinsic impedance of conductors is modified. Real couplings are also introduced.

\section{Comparison Between Modeling Methods on Simple EXAMPLES OF RETURN Plane}

\section{A. Case of Power Electronics Application}

A design constraint for power electronics applications implies the reduction of the sizes of devices. Therefore, it is not possible to accept large ground planes to dissipate the losses. The sizes of ground planes are usually the same as the ones of the circuit above them. Therefore, it is not possible to assume that sizes are infinite. Fig. 5 shows two circuits with different ground planes and their modeling with the classical image method. The equivalent inductance of the loop has also been measured.

In order to dissociate the effects, the distance between ground plane and conductors is constant (original image method) that is why, for low frequencies, the model is not so good. We have seen in the previous section the influence of this distance upon modeling.

In this simple example, we can see that the finite sizes of a return plane have an impact. The modeling using image method is no longer appropriated if return plane sizes cannot

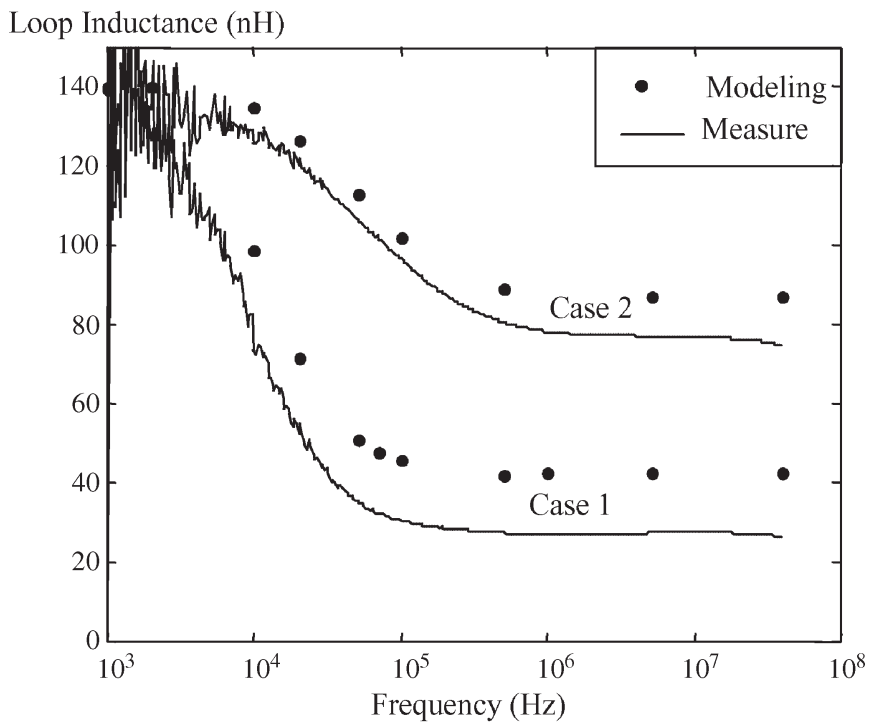

Fig. 6. Comparison between measures and modeling in the case of return planes as real conductors.

be considered as "big" compared with the sizes of the studied electrical equipment.

One solution is to describe the ground plane like a conductor as the other ones and to use the PEEC method to model the structure as shown in Section II. In order to model a nonuniform current density inside it, this new conductor is meshed. Since no assumption can be done upon the current direction, a 2-D meshing (see Fig. 1) has been applied. Moreover, its electrical equivalent circuit is coupled with the other conductors with mutual inductances. Its influence upon the current distribution as well as on the global losses can then be evaluated [9], [10].

This solution has been applied on the previous example, and results are shown in Fig. 6. The finite size influence is well modeled. The difference between the modeling and measure which appears for high-frequency domain is only due to an insufficient meshing of the return plane. It must be said that this meshing but be adapted to frequency to take into account the skin effect but this highly increases the number of subdivisions and, then, the matrix sizes for the circuit solving. That is why this difference is less important for case 2. In that case, return plane sizes are lower; therefore, the meshing can be denser than for case 1 with the same computational time. We can observe in Fig. 6 the well-known decrease of inductance with frequency due to the skin effect.

\section{B. Case of Transmission Line Application}

For high-frequency applications, the approach can follow the same way. Indeed, when the characteristics of the return plane avoid the use of the image method, it is possible to describe it as a conductor. Its meshing is simpler than in the previous case since the current is in only one direction. Then, the electrical characteristics of conductors above the return plane are modified. This modeling has been widely described in [11].

Figs. 7 and 8 show a test configuration and the comparison between measurements and modeling, respectively. 


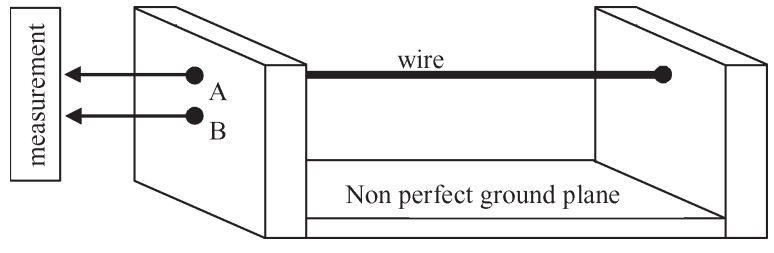

Fig. 7. Test configuration.

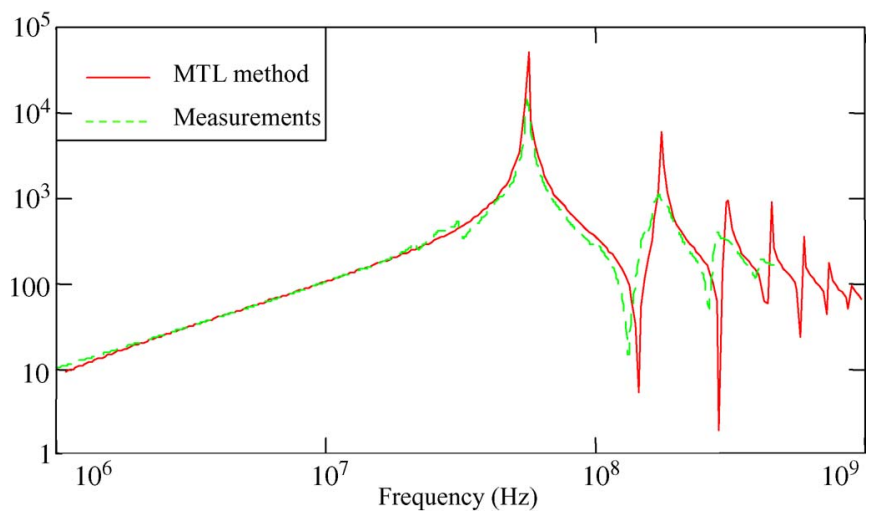

Fig. 8. Comparison between measures and modeling for the configuration in Fig. 7.

A good accuracy of results can be observed on this studied case.

Then, this modeling method has been successfully applied to more complex configurations. The only limit is the size of the matrix when solving the circuit equations of the whole problem.

\section{FEM}

Another way to model nonperfect return planes is to use the well-known FEM. This is the most common method used to numerically solve Maxwell equations for every kind of configuration [12]. Assuming a good meshing of the problem and adequate boundary conditions, the results are reliable. In this paper, it has not been used because PEEC and MTL approaches prevent the air meshing which is unavoidable for FEM. Nevertheless, its use can be justified when the assumptions of PEEC or MTL methods are not valid. It is particularly well adapted when nonlinear behaviors appear in the magnetic (conducting or not) materials.

\section{Conclusion}

To model nonperfect return planes, an alternative to the numerical solving of the Carson's integral can be the use of its geometrical and physical descriptions in order to find an electrical equivalent circuit. Then, according to frequency range or the geometrical configuration, the PEEC method which gives lumped elements or the MTL method which gives a per unit length model can be used, or FEM can also be well adapted if the described domain is not so large.

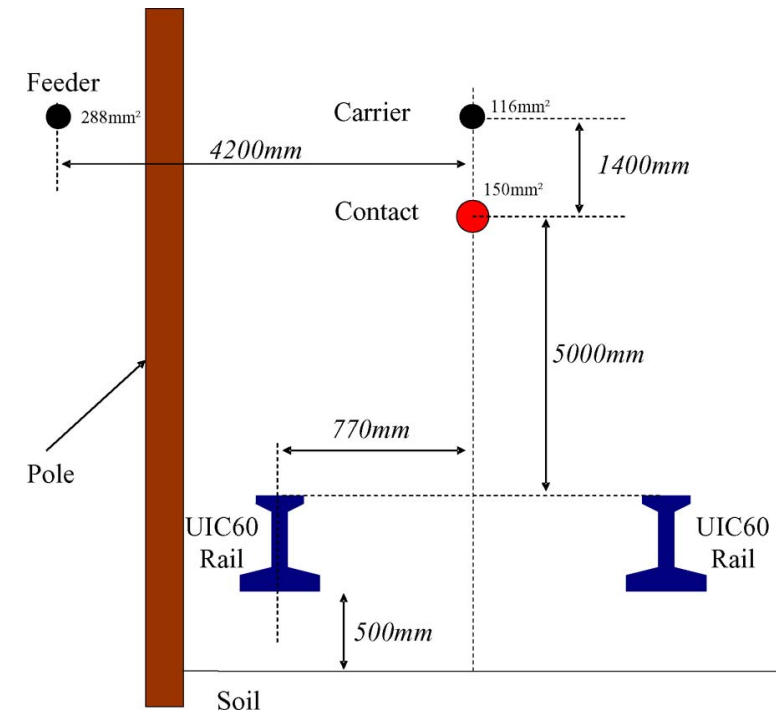

Fig. 9. Studied railway structure.

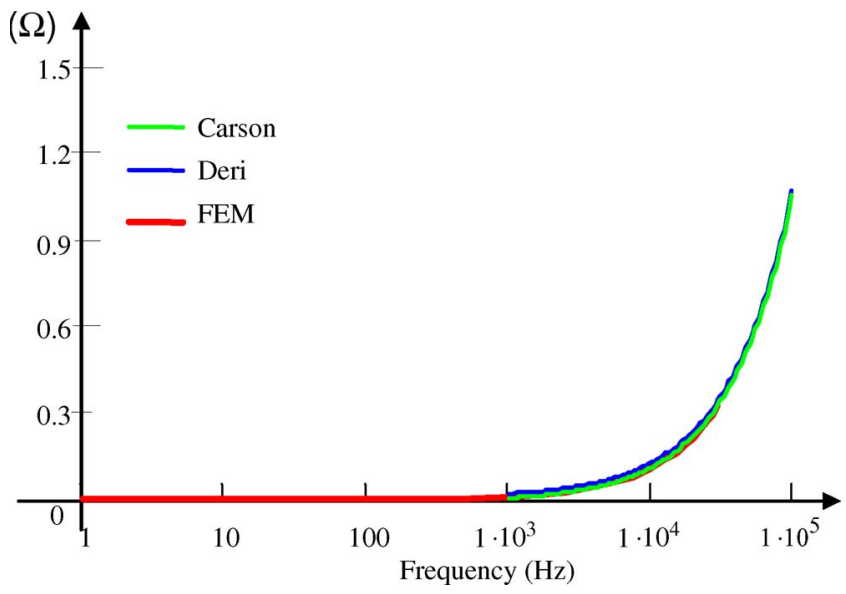

Fig. 10. Per-unit length impedance of the contact wire.

\section{Application to Railway System}

In this section, a railway application is detailed.

In fact, the return plane is the earth. Therefore, the assumption of a perfect ground plane is not valid in this case; its conductivity is not so high. Therefore, the classical image method is not valid, and we are going to compare results using modified image method and FEM, taking care of numerical hypothesis, so that results can be reliable.

The studied configuration is shown in Fig. 9.

It is a classical structure constituted of a feeder wire, a contact wire, a carrier wire, two rails, and the soil.

The electrical characteristics of each wire are evaluated either with the modified image method or the FEM.

A first comparison between the different modeling methods has been made. The per unit length electrical characteristics of each part of the structure have been evaluated and compared. Fig. 10 shows this comparison upon the per unit length impedance of the contact wire. These three modeling methods give the same results upon all the electrical characteristics of the structure (impedance and mutual impedance). Therefore, 


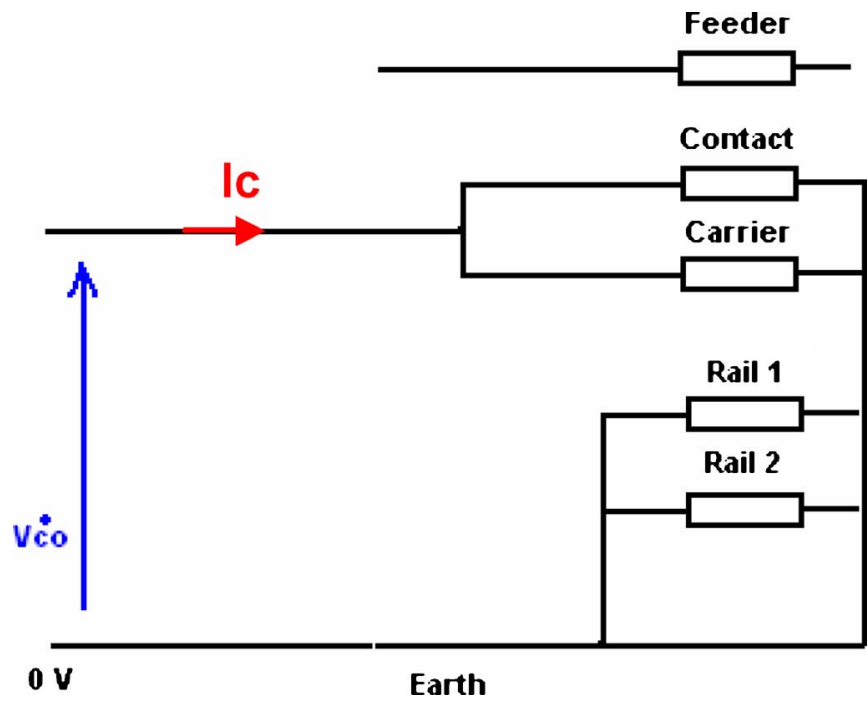

Fig. 11. Electrical connections of the studied configuration.

for the following comparison with measurements, only one of them is used.

After this first set of comparisons and evaluations upon the per unit length parameters, we have calculated the impedance of the configuration shown in Fig. 11. This is the configuration test on which measurements have been undertaken.

In order to evaluate the input impedance $Z_{0}$, it is necessary to take into account the length of wire $\ell$, the load impedance $Z_{c}$, and all other connections between the wires

$$
Z_{0}=V c o / I c .
$$

Then, (11) gives the current and voltage for any position $z$ along the wires.

$[Z]$ and $[Y]$ are the per unit length impedance and admittance matrices, respectively, using either Deri or MTL methods, $\gamma$ 's are their eigenvalues, and [T]'s are the eigenvectors

$$
\begin{aligned}
& \left\{\begin{array}{c}
\frac{\partial V(z)}{\partial z}=[Z][Y] \mathrm{V}(z) \\
\frac{\partial I(z)}{\partial z}=[Y][Z] I(z)
\end{array}\right. \\
& {[T]^{-1}[Y][Z][T]=\left[T^{\prime}\right]^{-1}[Z][Y]\left[T^{\prime}\right]=\left[\gamma^{2}\right]} \\
& \left\{\left(\begin{array}{cc}
I(0) \\
I(l)
\end{array}\right)=\left(\begin{array}{cc}
-[B]^{-1}[A] & {[B]^{-1}} \\
-[B]^{-1} & {[B]^{-1}[A]}
\end{array}\right)\left(\begin{array}{l}
V(0) \\
V(l)
\end{array}\right)\right.
\end{aligned}
$$

with

$$
\left\{\begin{array}{l}
{[A]=\frac{[Z c][T]\left(\left[e^{-\gamma l}\right]+\left[e^{\gamma l}\right]\right)[T]^{-1}[Z c]^{-1}}{2}} \\
{[B]=\frac{[Z c][T]\left(\left[e^{-\gamma l}\right]+\left[e^{\gamma l}\right]\right)[T]^{-1}}{2} .}
\end{array}\right.
$$

Fig. 12 shows the evaluation of impedance $Z_{0}$, and Fig. 13 shows the measurements on the test configuration.

The measurement conditions have not been clearly established; therefore, it has been difficult to compare measurements and simulations. For example, a power substation with a threephase transformer is in the close neighborhood of the railway measured loop. This electrical equipment has not been model even if it is well known that electromagnetic field can be influent and can modify the impedance value. Since no information

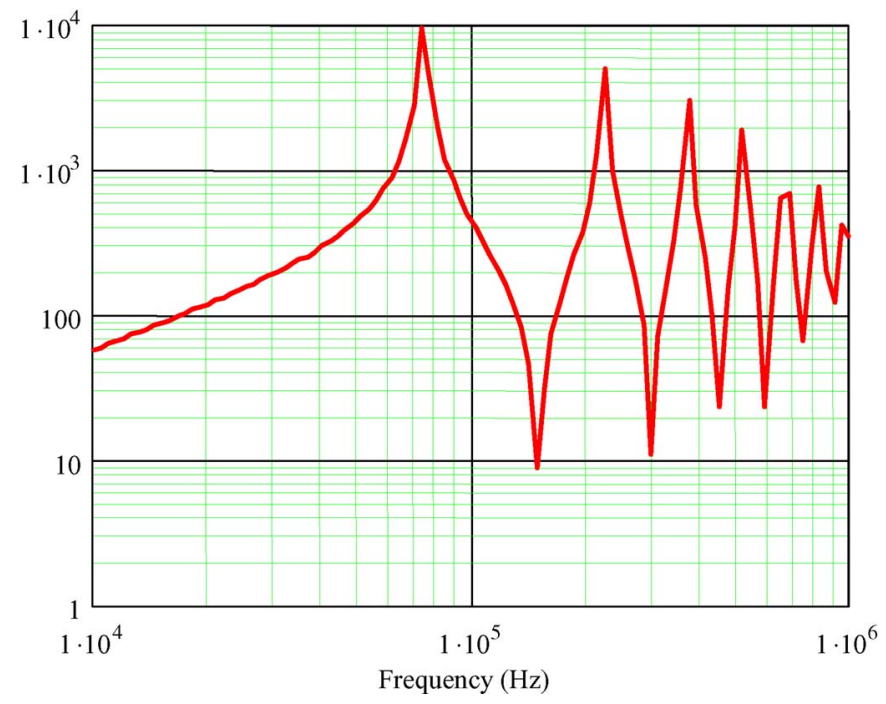

Fig. 12. Evaluation of $Z_{0}$.

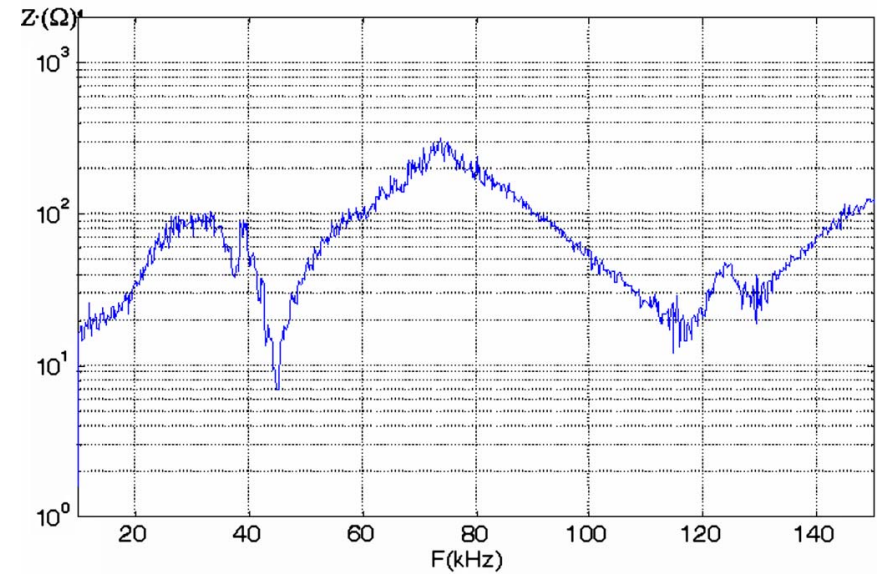

Fig. 13. Measurements.

has been given concerning it by the private company, it was not possible to model it to obtain better results.

Some assumptions on the connections between the wires have been made without certainty.

Nevertheless, a good agreement on the behavior can be observed. The characteristic frequencies are well evaluated as well as the low frequency impedance.

This kind of model for connections can complete the model which is used in [13] in order to design a multilevel hybrid power filter for railway applications.

Moreover, this modeling process is well adapted to the design of every kind of connection. The equivalent impedance can be used to evaluate the EMI performances of systems such as those presented in [14] or [15].

\section{CONCLUSION}

This paper has presented different methods to model a return plane for electrical structures. Three approaches were detailed according to the assumptions which are valid on the studied device. This is not an exhaustive list of modeling methods but a practical way to take into account nonperfect return planes. 
The PEEC method is well adapted to give an electrical equivalent circuit of connections. Coupled with the image methods, high conductivity return planes can be modeled.

If the conductivity or sizes are not so high, the image method can be used if distance is modified and skin depth or complex distance is added.

For high-frequency applications, a transmission line method is preferred. In that case, the MTL method is used to evaluate the electrical equivalent circuit of connections.

The FEM can be used for every kind of application, assuming that it is correctly used. For some cases, it can be used as a reference method to test other models. However, calculus with this method can require heavy memory and a very long time for calculation.

The railway application which has been presented is a good example to show interest in such a modeling.

\section{REFERENCES}

[1] A. E. Ruehli, "Inductance calculations in a complex integrated circuit environment," IBM J. Res. Develop., vol. 16, no. 5, pp. 470-481, Sep. 1972.

[2] A. E. Ruehli, "Equivalent circuit models for three-dimensional multiconductor systems," IBM J. Res. Develop., vol. 22, pp. 216-221, 1974.

[3] J. Aimé, J. Roudet, C. Vollaire, P. Baudesson, and P. Ecrabey, "Layout techniques for reduction of common mode current in static converters," in Conf. Rec. 41st IEEE IAS Annu. Meeting, Oct. 8-12, 2006, vol. 5, pp. 2296-2303.

[4] J. M. Guichon, J. Aimé, J. L. Schanen, C. Martin, J. Roudet et al., "Busbar design: How to spare nanohenry?" in Conf. Rec. IEEE IAS Annu. Meeting, FL, Oct. 2006, pp. 1865-1869.

[5] R. P. Clayton, Analysis of Multiconductor Transmission Lines (Wiley Series in Microwave and Optical Engineering). Hoboken, NJ: Wiley, 1994.

[6] A. Deri, G. Tevan, A. Semlyen, and A. Castanheira, "The complex ground return plane: A simplified model for homogeneous and multi-layer earth return," IEEE Trans. Power App. Syst., vol. PAS-100, no. 8, pp. 36863693, Aug. 1981.

[7] J. R. Carson, "Wave propagation in overhead wires with ground return," Bell Syst. Tech. J., vol. 5, pp. 539-554, 1926.

[8] T. Noda, "A double logarithmic approximation of Carson's ground return impedance," IEEE Trans. Power Del., vol. 21, no. 1, pp. 472-479, Jan. 2005.

[9] J-P. Gonnet, E. Clavel, V. Mazauric, and J. Roudet, "PEEC method dedicated to the design of electrical systems," in Proc. PIERS, Pisa, Italy, Mar. 28-31, 2004.

[10] E. Clavel, J. Roudet, A. Orlandi, S. Cristine, and G. Antonini, "Conducted and radiated EMI characterisation of power electronics converter," in Proc. IEEE ISIE, Guimaraes, Portugal, Jul. 7-11, 1997, pp. SS 207SS 211.

[11] E. Clavel, J. Roudet, and J. L. Schanen, "A multiconductor transmission line method to study non-perfect ground planes," in Proc. EMC-ZURICH, 1999.

[12] A. Nicolet, F. Delince, N. Bamps, and A. Genon, "A coupling between electric circuits and 2D magnetic field modeling," IEEE Trans. Magn., vol. 29, no. 2, pp. 1697-1700, Mar. 1993.

[13] S. Rahmani and K. Al-Haddad, "A single phase multilevel hybrid power filter for electrified railway applications," in Proc. IEEE Int. Symp. Ind. Electron., Jul. 9-13, 2006, vol. 2, pp. 925-930.

[14] W. Chen, X. Yang, and Z. Wang, "Analysis of insertion loss and impedance compatibility of hybrid EMI filter based on equivalent circuit model," IEEE Trans. Ind. Electron., vol. 54, no. 4, pp. 2057-2064, Aug. 2007.

[15] W. Shuo, J. D. van Wyk, and F. C. Lee, "Effects of interactions between filter parasitics and power interconnects on EMI filter performance," IEEE Trans. Ind. Electron., vol. 54, no. 6, pp. 3344-3352, Dec. 2007.

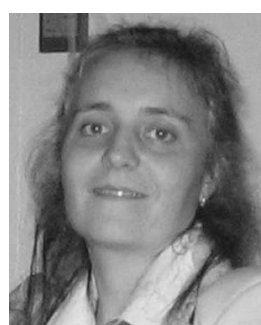

Edith Clavel received the Engineer and Ph.D. degrees in electrical engineering from the Institut Polytechnique de Grenoble, Grenoble, France, in 1993 and 1996, respectively.

She is an Assistant Professor with University Joseph Fourier, Grenoble. She has been a permanent Researcher with the Grenoble Génie Electrique Laboratory, Grenoble, since 1996, in the field of power electronics. Her main activities concern the modeling and design of any kind of connections of power structures, massive bars, bus bars, printed circuit boards, etc. Her research team develops a tool (InCa3D) which models and optimizes connections in order to improve the performances of power structures, including electromagnetic compatibility and thermal aspects.

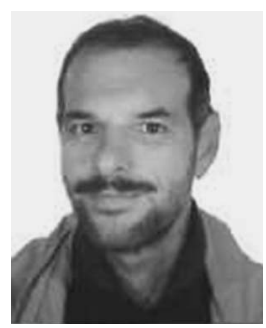

James Roudet received the Engineer and Ph.D. degrees in electrical engineering from the Institut Polytechnique de Grenoble, Grenoble, France, in 1986 and 1990, respectively.

$\mathrm{He}$ is a Professor with the Power Electronics Team, Grenoble Génie Electrique Laboratory (G2ELab), University Joseph Fourier, Grenoble, where he is the Head of the G2ELab. His main activities concern the technological design of power converters. His research team uses (or develops if not available) any kind of modeling tools in order to improve the performance of power electronics converters, including electromagnetic compatibility and thermal aspects.

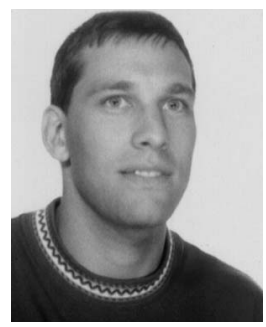

Thierry Chevalier received the Engineer and $\mathrm{Ph} . \mathrm{D}$. degrees in electrical engineering from the Institut Polytechnique de Grenoble, Grenoble, France, in 1995 and 1999, respectively.

$\mathrm{He}$ is an Assistant Professor with the National Polytechnic Institute of Grenoble, Grenoble. He is with the Grenoble Génie Electrique Laboratory, Grenoble, where he is working with the team specialized in numerical methods and calculations for electromagnetics. He is specialized in formulations of electromagnetic problems in finite element methods, and his mains topics of research are actually the development of new computation environments for multimethod approaches in electromagnetic calculations.

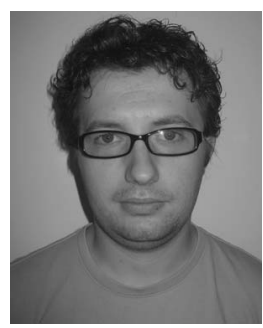

Dragos Mihai Postariu was born in Pitesti, Romania, in 1983. He received the B.S. and M.S. degrees from the Ecole Nationale Supérieure d'Ingénieurs Electriciens de Grenoble, Grenoble, France, in 2006, both in electrical engineering. He is currently working toward the Ph.D. degree in the Grenoble Génie Electrique Laboratory, Grenoble, France, with the thesis "The degradation of bearings due to runaway currents." 